\title{
Erratum to: The goldfish conditioned withdrawal preparation: effects of some basic methodological variables
}

\author{
Peter B. Barela ${ }^{1}$
}

Published online: 16 June 2015

(C) Psychonomic Society, Inc. 2015

Erratum to: Learn Behav

\section{DOI 10.3758/s13420-015-0181-2}

On the first page, right column, line 6 , the cent symbol $(\phi)$ should be inserted after " 20 ". Thus, the text should read: ...(less than $\$ 200$ for materials, and less than 20 capiece for feeder goldfish).

Springer regrets the error.

The online version of the original article can be found at http://dx.doi.org/ 10.3758/s13420-015-0181-2.

$\triangle$ Peter B. Barela

peter.barela@yahoo.com

1 Henderson, CO, USA 